\title{
Scleral indentation without resection
}

\author{
K. RUBINSTEIN AND B. G. HAYES \\ Birmingham
}

An era of the rational treatment of detachment of the retina began with the work of Gonin (1925). Before this there was little or no hope of successful treatment. Gonin's technique involved the closure of retinal tears or holes by the formation of adhesions between the choroid and retina. Since then various refinements of surgical technique have been introduced, but the basic principle of Gonin remains unchanged.

In the more advanced cases of retinal detachment, such as those with gross ballooning of the retina with vitreous traction or multiple holes, the production of coagulation by heat or caustics could not be expected to seal the retinal perforation. It was these circumstances that led Lindner (1934) to introduce an operation for shortening of the sclera as a means of reducing the volume of the globe. In the operation of perforating sclerectomy a meridional slip of full-thickness sclera was excised. It is interesting to note that the resection of a circumferential band of sclera $4 \mathrm{~mm}$. in width in the equatorial region of the globe leads to a reduction in the volume of the vitreous chamber of 6 o per cent. The work of Lindner remained the mainstay of the treatment of retinal detachment for about 15 years. He then published a paper setting out the position at that time: "Shortening of the Eyeball for Detached Retina" (Lindner, 1949).

The operation of full-thickness scleral resection is technically difficult owing to the liability of rupture of the choroid and retina with consequent escape of vitreous.

Shapland (I95I) advocated a safer procedure-lamellar scleral resection. In this operation a meridional strip consisting of the outer two-thirds of the scleral layers was excised, the base of the resected area was then cauterized with potassium hydroxide, a puncture was made to allow the subretinal fluid to escape, and the edges of the resected area were drawn together by interrupted sutures. Thus a ridge was made to project into the eye; closure of the retinal hole was attained by the application of diathermy. The height of the ridge was increased by Chamlin and Rubner (1956) by embedding the outer strip of sclera instead of excising it.

Indentation or buckling of the sclera using an implant of inert material was a logical extension of this, and Schepens (1953) implanted a polyethylene tube in the groove of a lamellar sclerectomy; implants were also inserted after undermining a pocket of sclera to deal with a more localized area.

The final step was taken (Schepens, Okamura, and Brockhurst, 1957) by the insertion of a circumferential tube of polyethylene in the equatorial region to produce a circular ridge within the eye. This material has now been replaced by silicone rubber owing to the danger of infection and ulceration of the sclera. A portion of the encircling strap may be embedded to produce a ridge of greater height in a localized area. A simplified encircling operation was advocated by Arruga (1960), who tied a Supramid thread round the eye near the equator. 
The value of lamellar scleral resection depended on the internal tucking of the sclera and choroid to form a ridge within the eye. The idea that this could be achieved witho equal success by full-thickness indentation of the sclera was exploited by Custodis (1953), who sutured a polyviol implant to the sclera specifically for this purpose; chorioretinal adhesions were produced by diathermy.

The main cause of dissatisfaction with diathermy is the damaging effect which it $\frac{\overline{\bar{c}}}{\overline{\frac{\omega}{\sigma}}}$ produces in the sclera, where it may lead to areas of necrosis. With the use of plastics for $\stackrel{\mathbb{\Phi}}{\varrho}$ scleral buckling these necrotic areas easily become sites of infection. This fact, together with the modern industrial development of cryogenics, led to a renewal of ophthalmic $\overrightarrow{0}$ interest in cryopexy as a means of producing chorioretinal adhesions in detachment $\overrightarrow{\vec{\omega}}$ surgery. Cryopexy has been shown experimentally by Lincoff, McLean, and Nano (I 964$), \stackrel{\omega}{\circ}$ and Lincoff and McLean (1966), not to cause scleral necrosis. Therefore, by its use ino. place of diathermy, it is possible to eliminate the main complication of full-thickness $\omega$ scleral buckling using an implant of synthetic material while still producing chorioretinal adhesions.

In the United Kingdom the first cases operated on by this modified Custodis technique with cryopexy were reported from Birmingham (Rubinstein, 1965, 1966), and the technique has since been adopted in many major centres.

We now wish to present a review of a further series of cases in which this technique has been used, either as a local full-thickness scleral indentation or as an encircling procedure, with or without a buckle, but always without scleral resection. Cryopexy was used $\stackrel{\mathbb{D}}{-}$ throughout as described previously (Rubinstein, I966).

\section{Clinical material}

This series is composed of all consecutive patients who presented with idiopathic retinal detachment at our out-patienı departments (KR) of the Birmingham and Midland Eye Hospital and Selly Oak Hospital during the years 1966 and 1967 . The follow-up time of from $\mathrm{I}$ to 3 years is thought to allow an assessment of the value of the technique. Fifty patients were involved, four of whom had bilateral detachments; 54 operations were performed as a primary procedure, and sixteen cases $\bigcirc$ required further surgery, making a total of seventy operations.

The age and sex distribution of the series is shown in Fig. I. As expected, because retinal detach-o ment is associated with degenerative changes in the retina and vitreous body, the majority of those․․ affected are in the older age group. The sexes in this series are represented in approximately equal: proportions.

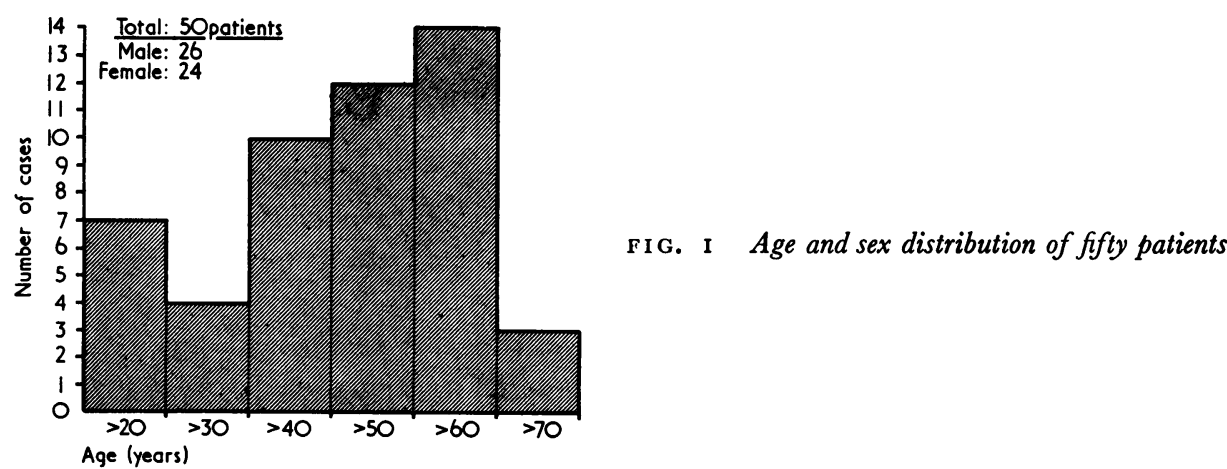

All grades of detachment were encountered; no case was regarded as inoperable during these years although some appeared to be hopeless from the beginning. The type and number of retinal breaks $\frac{\mathrm{O}}{\mathbb{8}}$ were as follows: round holes 36 ; arrow heads 41 ; dialysis 7 ; giant tears 5 . 


\section{Technique}

PRIMARY PROCEDURES

The following methods were used in the primary series of seventy operations: Custodis 37; cerclage 27 ; scleral resection 2; cryoapplication alone 2; light coagulation alone 2.

In four cases the retina became flat enough after rest in bed to be treated by either cryoapplication or light coagulation alone. In only one case was an intravitreal injection of air required to bring the ocular tension up to normal at the end of the operation.

BUGKLING MATERIAL

Those used were as follows: silicone rubber 6o cases; silicone sponge 4 cases; sclera (resection) 2 cases; none 4 cases.

THERMAL AGENTS

The following were used: cryoapplication 66 cases; diathermy 2 cases; light coagulation 2 cases.

MUSCLE SURGERY

A single muscle was detached in thirty cases, and none in the rest.

\section{Hospitalization}

Postoperatively the patients were given a 5-day course of tetracycline. The second eye was uncovered after 48 hours, excessive movement being prevented by the use of Lochbrilles (pinhole spectacles). The patients started getting out of bed within a week; $5^{8}$ per cent. were discharged from the ward within 2 weeks after the operation and a further 33 per cent. within the third week; only 9 per cent. required hospitalization for over 3 weeks because of reoperation (Fig. 2).

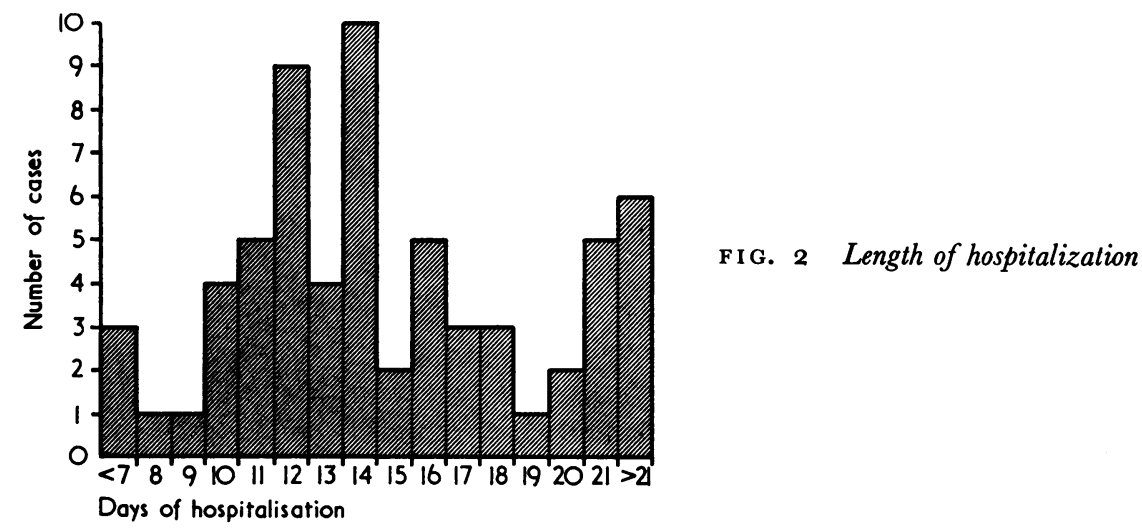

\section{Reoperation}

Sixteen reoperations were required and half of these followed a failure to attach the retina by the primary procedure. These patients formed the majority of those hospitalized for over 2 weeks; one patient with bilateral giant breaks associated with cataract formation and uveitis spent over 2 months in the wards. The other eight developed a fresh detachment after being discharged with well-appositioned retinae.

It is interesting that reoperated cases did not belong necessarily to the "large tear-large detachment" group. Only one eye required more than one reoperation. The patient 
was a 40-year-old man who had lost the other eye as a result of retinal detachment io years before. There was a shallow peripheral temporal detachment with minute breaks which kept recurring in situ, in spite of a local implant, strap and buckle, and further local $\vec{F}$ implant. After three re-operations the retina has remained flat for the past 2 years, but $\bar{c}$ the macula soon developed degenerative changes.

Of the fourteen eyes reoperated, eight ended with a flat retina and six were failures (Table).

Table Cases needing reoperation

\begin{tabular}{lll}
\hline Total eyes & Reoperations & Total reoperations \\
\hline I & I planned reoperation & I \\
I & 3 reoperations & 3 \\
I & I reoperation & I2 \\
\hline I4 & & I6
\end{tabular}

Reoperation was performed within 2 weeks in eight cases, 2 months in four cases, and 4 to 8 months in four cases.

\section{Failures}

Of the 54 eyes operated upon, the retina failed to re-attach in fourteen (25.9 per cent.). $\vec{\bullet}$ The pre-operative conditions in this group were as follows: diabetes with proliferations $2 ; .6$ marked uveitis 2 ; aphakia 3 ; bilaterality 4 ; juvenile 5 ; giant tears and dialysis 5 .

In fact, we considered most of them to carry a very poor prognosis pre-operatively: for instance, diabetics with retinal proliferation and vitreous bands or the juvenile group, which included a case of bilateral post-choroiditis vitreous traction, one of retinoschisis $\mathbb{D}$ with large dialysis, one of bilateral giant breaks with uveitis, one following a Fukala operation, and one of extreme myopia $(-32 \mathrm{D})$ with the other eye affected by retinoschisis. There were, however, four cases in this group in which a successful re-attachment was envisaged but eventually not achieved.

\section{Results and conclusions}

In fourteen cases, as shown above, the retina remained detached in spite of surgery. Of the remaining forty cases $\left(74^{\circ} \mathrm{I}\right.$ per cent.), two (3.7 per cent.) showed during a 2-year follow-up a stationary small area of retinal elevation, which probably at first represented a $\frac{}{5}$ pocket of subretinal fluid, and eventually a fixed retinal fold; in the other $3^{8}$ cases $(70 \cdot 4 \stackrel{\text { ? }}{2}$ per cent.), the retinae were well attached in situ. Although a high rate of success with retinal detachment surgery can be achieved by various surgical techniques, our figure of $\%$ 74 per cent. in these unselected consecutive cases seems to stand comparison with other $\tilde{N}$ reported series. This success rate was achieved by a simple atraumatic technique which $\mathrm{N}$ presents the following advantages:

(I) 60 per cent. of all our detachments could be repaired by a local, modified Custodis procedure. Only four of these cases which had to be reoperated (Io per cent.) were? successfully repaired at reoperation by using the strap and buckle technique. In the fourteen failures, a local implant had been used as a primary procedure in six, and the strap and buckle in eight cases. This type of operation should not take more than one hour, and it leaves an eye less disturbed than does an operation for squint. 
(2) If the retinal holes are off centre, shifting of the buckle requires only the re-insertion of a few new sutures. This can be done after the final check of the fundus when the buckle is well formed. Resection, on the other hand, either as a primary procedure or in burying the buckle, makes later adjustment of the position of the buckle impossible.

(3) The buckles obtained with this technique may be made as steep as required to effect retino-choroidal contact and their height may be regulated. Restitution of intraocular pressure by intravitreal injections becomes unnecessary, especially as the length of the buckle may also be adjusted at leisure at the time of the operation.

(4) With a strap-and-buckle technique, the strap does not need to be made too tight; a judiciously placed buckle is instead infolded by separate mattress sutures, thus giving a steep support where required. The complications resulting from too tight a strap are thus avoided, while the required permanent indentation is created in place of dispersed subretinal fluid.

(5) A strap-and-buckle operation without resection does not take much longer than the local procedure.

(6) Cryopexy through full-thickness sclera is effective and does not damage the sclera. We had no cases of scleral abscess, either in the present series or since I 965 when the method was adopted. The experience of Lincoff and McLean (1966) with 200 cases was similar. Diathermy used with this technique may be dangerous.

(7) Because the eye becomes quiet soon after operation and the holes are firmly placed over steep buckles, the patient's stay in hospital is shortened.

\section{References}

ARruga, H. (1960) "Experiencia de 120 casos de desprendimiento de la retina operados con el anillo ecuatorial", in "Congreso Panamericano de Oftalmologia, Caracas, 1960"

ChAmlin, M., and RUBNer, K. (1956) Amer. F. Ophthal., 41, 633

custodis, E. (1953) Ber. dtsch. ophthal. Ges., 58, 102

GONIN, J. (1925) Bull. Soc. frans. Ophtal., 38, 6 I4

Lincoff, н. A., and mclean, J. м. (1966) Trans. Amer. Acad. Ophthal. Otolaryng., 70, 202

$\longrightarrow,-$, and NANO, H. (1964) Ibid., 68, 412

LINDNER, K. (1934) Z. Augenheilk., 81, 277

- (1949) Arch. Ophthal., 42, 634

RUBinsteIN, K. (1965) Trans. ophthal. Soc. U.K., 85, 555

- (1966) Proc. roy. Soc. Med., 59, 1068

SCHEPENS, G. L. (I953) Amer. F. Ophthal., 36, 1739

- OKamura, I. D., and Brockhurst, R. J. (1957) A.M.A. Arch. Ophthal., 58, 797

SHAPLAND, C. DEE (I95I) Trans. ophthal. Soc. U.K., 7I, 29 